\title{
INTEREACE
}

Sociologias, Porto Alegre, ano 10, no 19, jan./jun. 2008, p. 250-273

\section{A mídia e o declínio da confiança na política}

LUIS FELIPE MIGUEL*

1. Introdução

"A política tem a sua fonte antes na perversidade do que na grandeza do espírito humano"

(Voltaire)

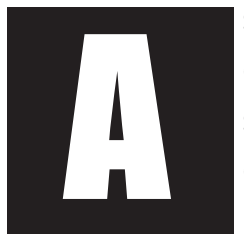

s pessoas não confiam nos políticos ${ }^{1}$. A frase de Voltaire, escrita no século XVIII, expressa algo que se aproxima do senso comum do século XXI. Os integrantes da elite política, aqueles que ocupam ou almejam ocupar os cargos de poder da estrutura de Estado, são vistos como auto-interessados, oportunistas, inconfiáveis, desprovidos de princípios, egoístas e, mesmo, corruptos. Na atividade política, encontram vantagens pessoais, prebendas, mordomias. Um fosso os separa dos cidadãos comuns, que vivem do próprio trabalho e enfrentam as dificuldades do dia-a-dia.

Em diferentes graus, essa percepção negativa dos políticos está presente em países ricos e pobres, em velhas e novas democracias. Vários indicadores mostram, tanto um declínio na confiança em relação aos indivíduos que compõem a elite política, quanto um crescente ceticismo a res-

\footnotetext{
* Professor do Instituto de Ciência Política da Universidade de Brasília e pesquisador do CNPq, emails: Ifelipe@unb.br; Ifelipemiguel@uol.com.br.

1 Agradeço os comentários e sugestões de Regina Dalcastagnè e Helena Máximo, que leram versões anteriores do texto.
} 
peito da efetividade das instituições que se propõem realizar a democracia política (eleições, partidos, parlamento). Na virada do século XX para o século XXI, a ciência política descobriu o fenômeno, que foi então caracterizado como sendo o "paradoxo democrático" (Dahl, 2000), ou a emergência dos "cidadãos críticos" (Norris, 1999). Isto é, cidadãos que combinam um alto grau de adesão aos valores da democracia política (igualdade, soberania popular, etc.) a uma completa falta de fé nos mecanismos institucionais que, no Ocidente, estão associados a ela.

Diante deste fenômeno, boa parte da literatura adota um tom condenatório, culpando os cidadãos por alimentarem expectativas excessivas quanto ao funcionamento da democracia (Sartori, p.86-122, vol.1, 1987; Norris, 1999, p.11). Pode-se, no entanto, julgar que o ceticismo em relação ao funcionamento das instituições da democracia eleitoral é fruto de uma avaliação realista de seu funcionamento, já que, por diversos motivos e a despeito do tributo ritual à vontade soberana do povo, elas se mostram bastante impermeáveis à influência das pessoas comuns (para um aprofundamento deste ponto, ver Miguel, 2005).

Neste artigo, o foco se concentra no declínio da crença de que os governantes - ou os políticos em geral - podem ser bem-intencionados e competentes. De maneira algo provocativa, mas sem excessiva simplificação, é possível apresentar três explicações gerais para este fato:

(a) a hipótese do cinismo crescente do público, segundo a qual a elite política atual é tão boa quanto a do passado, mas os cidadãos se tornaram incapazes de apreciar suas virtudes;

(b) a hipótese do fim das ilusões, para a qual a elite política do passado é tão ruim quanto a atual, mas o público só agora abriu os olhos e deixou de ser enganado como era antes; e (c) a hipótese da percepção popular correta continuada, que entende que a qualidade média da elite política decaiu e, no passado como agora, o público é capaz de avaliá-la de forma acertada. 
(Uma quarta explicação é logicamente possível, mas está ausente da literatura: uma hipótese da percepção popular incorreta continuada, segundo a qual, por algum motivo, os cidadãos sempre avaliariam erroneamente a elite política, julgando-a boa quando era má e má agora que se tornou boa).

Em qualquer uma das três narrativas, os meios de comunicação de massa cumprem um papel crucial, seja alterando as disposições do público, seja influenciando na qualidade da elite política. Após uma breve exposição dos dados que indicam a crescente insatisfação com os políticos, o artigo expõe e discute com maior vagar as diferentes explicações para o fenômeno, enfatizando o papel da mídia em cada uma delas. Ao final, é realizado um balanço comparativo, com a apresentação de um esboço de uma explicação divergente, em que à mídia é concedido um papel menos protagônico.

\section{O declínio da confiança}

É razoável construir uma trajetória que parte da "crise da democracia", identificada por pensadores conservadores nos anos 1970, e chega à dissolução da confiança nos governantes. Na versão mais influente, de Samuel Huntington, a ativação popular iniciada no final dos anos 1960 (rebelião estudantil e operária em várias partes do mundo, ofensiva feminista, mobilização contra a Guerra do Vietnã, crescimento e radicalização do movimento pelos direitos civis dos negros nos Estados Unidos) demonstrou a "ingovernabilidade" das democracias. A ampliação da quantidade e variedade de grupos mobilizados gerava um excesso de demandas sobre os Estados, que os governos democráticos, reféns do voto popular, tentavam atender, sem possuir recursos para tanto. O resultado era ineficiência, erosão da autoridade e frustração (Huntington, 1975).

Por trás do diagnóstico, havia o entendimento de que o bom funcionamento de um regime democrático exigia a disseminação de uma "cultura cívica" tal como a descrita por Almond e Verba (1963). Nela, há (a) uma 
alta confiança na permeabilidade do sistema político à ação dos cidadãos, mas (b) poucas tentativas de testar esta crença. Isso garante uma grande adesão ao regime, percebido como intérprete da vontade popular, sem tensioná-lo com pressões em excesso. Na percepção de Almond e Verba, tal cultura cívica imperava nos Estados Unidos, no momento em que realizam sua pesquisa empírica (final dos anos 1950) e se encontrava em construção em outros países de democracia concorrencial.

A "ingovernabilidade" detectada nos anos 1960 aparece como efeito de uma deficiência no funcionamento de (b). O ativista acredita que, por meio da ação coletiva, é possível garantir o atendimento a certas reivindicações - portanto, mobiliza-se e pressiona o Estado. O refluxo verificado nas décadas mais recentes aponta para o problema contrário, o declínio de (a). Os cidadãos se mobilizam relativamente pouco, mas porque crêem que o sistema político não lhes dará ouvidos. De um jeito ou de outro, erode-se a cultura política ideal para a manutenção da estabilidade das democracias, tal como pensavam Almond e Verba.

A percepção de que há uma descrença generalizada nas potencialidades da política institucional se sustenta em vários tipos de evidências, dentre os quais se destacam o aumento da abstenção eleitoral, a erosão das lealdades partidárias e os resultados de surveys sobre confiança no sistema e nas elites políticas, realizados periodicamente. Eventos pontuais como escândalos de corrupção e abuso de poder que, nas últimas duas décadas, afetaram governantes de inúmeros países, e o sentimento de "inutilidade da política", produzido pelo fracasso das alternativas socialistas e pelo crescente poder das corporações privadas, podem ter acelerado o processo, mas não dão conta de explicar, sozinhos, seu desencadeamento.

Esforços de análise sobre os motivos da crise de confiança nas instituições representativas se sucederam a partir do final dos anos 1990, destacando-se os volumes organizados por Pippa Norris, Critical citizens (1999), e por Susan Pharr e Robert Putnam, Disaffected democracies (2000), ambos 
com uma perspectiva comparativa, e por Joseph Nye, Jr., Philip Zelikow e David King, Why people don't trust government (1997), mais focado nos Estados Unidos. Todos são unânimes em apontar que a ampliação da descrença pouco se relaciona com um declínio do desempenho econômico, ou mesmo, com a existência de mais corrupção. De fato, dentre 17 possíveis "hipóteses" sobre o declínio da confiança no governo, aquelas que são consideradas mais robustas por Nye e Zelikow são as que se referem ao efeito da Segunda Guerra Mundial (que gerou uma adesão anormalmente alta aos governos nacionais, o que levaria a uma queda relativa posterior), ao realinhamento político das elites, à terceira revolução industrial e à emergência dos valores "pós-materialistas", além dos efeitos da TV na política e à mudança no papel da mídia (Nye e Zelikow, p.269-70, 1997).

\section{A espiral do cinismo}

A primeira das três explicações esquemáticas à pergunta "por que as pessoas não confiam mais nos políticos", apresentadas acima, responsabiliza a desconfiança excessiva do público atual. Sua formulação mais completa se encontra na hipótese da "espiral do cinismo", desenvolvida no livro de mesmo nome de Joseph N. Cappella e Kathleen Hall Jamieson (1997). Se os políticos se tornaram cínicos, isto se deu em reação ao cinismo dominante no público. O elemento central, porém, seria a mídia, responsável por difundir uma imagem negativa dos agentes da esfera pública.

Já a partir do nome conferido à hipótese, verifica-se a intenção de apresentá-la como um desdobramento da famosa "espiral do silêncio" de Elisabeth Noelle-Neuman (1993). De acordo com a pesquisadora alemã, homens e mulheres receiam, acima de tudo, o isolamento social, o que os levaria a se adaptarem às opiniões que julgam predominantes e a silenciar posições dissidentes. As perspectivas privilegiadas pelos meios de comunicação parecem ser majoritárias. Como aqueles que pensam diferente se 
calam, temendo o isolamento, nossa vivência confirmaria a impressão gerada pela mídia - eis o mecanismo da espiral.

Para Noelle-Neuman, trata-se de um efeito que se exerceria sobre a manifestação pública de opiniões ou preferências. Já a hipótese de Cappella e Jamieson diz respeito a mudanças não apenas na expressão, mas na própria percepção dos cidadãos sobre o mundo social. A hipótese é que existiria um círculo vicioso de realimentação entre a cobertura da imprensa sobre a política, as expectativas do público e o comportamento dos políticos. O cinismo de cada um reforçaria o cinismo dos outros: os políticos perceberiam que não vale a pena manter uma postura republicana que priorize o bem comum, já que sempre serão encarados como auto-interessados e carreiristas; os jornalistas saberiam que seus leitores esperam uma leitura da política neste diapasão; o público veria sua crença no desregramento dessa atividade, confirmada tanto pelo noticiário, quanto por seus eventuais encontros com os políticos.

Fica claro que o principal motor do processo é a mídia. Há, pelo menos, três razões que ajudam a explicar por que a cobertura da política pela imprensa tende a ser cínica. Em primeiro lugar, haveria a influência de uma "ideologia profissional", segundo a qual o bom jornalista deve desconfiar das aparências, não aceitar o que lhe dizem pelo valor de face e buscar aquilo que está encoberto. Se tal postura é, em linhas gerais, saudável, ao mesmo tempo descambaria com facilidade para o cinismo - a passagem do "nada deve ser aceito sem questionamento" para o "todos sempre têm motivos escusos ocultos".

Em seguida, haveria o fenômeno da especialização profissional dos jornalistas. O repórter de política entende de política e nada mais, isto é, tem incentivos fortes para fazer uma cobertura "hiperpolitizada" da própria política. Todos os eventos - nomeações, medidas governamentais, planos de ação, plataformas eleitorais, conflitos de idéias - seriam imediatamente traduzidos em termos de seu impacto na disputa política. O repórter não é 
capaz de avaliar o real efeito de uma proposta de reforma educacional ou no sistema de saúde, por exemplo, mas sabe especular sobre a influência que pode ter nos jogos do poder, como afeta a carreira política de seus promotores, quais grupos de pressão beneficia, quais apoios eleitorais em potencial ela adiciona ou retira. Nas palavras de um crítico da mídia estadunidense, cuja posição se aproxima da hipótese da "espiral do cinismo":

O instinto natural dos jornais e da TV é apresentar qualquer questão pública como se seu significado real fosse político, no sentido mais estreito e operacional do termo - as tentativas dos partidos e de seus candidatos de ganhar vantagens sobre seus rivais (Fallows, p.37, 1996).

O problema não reside tanto em reconhecer a dimensão "política" (no sentido estreito e operacional definido por Fallows) das questões públicas, mas em resumi-las a isso. Todas as ações de governo, todas as disputas programáticas e todas as iniciativas no campo das políticas públicas ficariam, assim, resumidas a meras fachadas, uma vez que o único objetivo relevante seria, sempre, obter votos (ou o apoio de operadores políticos relevantes) e alavancar carreiras políticas ${ }^{2}$.

Por fim, existiriam incentivos formais tanto à abordagem estratégica da política, quanto ao foco nos malfeitos dos políticos. O escândalo e o erro sempre são notícias, seus contrários não, como os governantes não se cansam de reclamar. Giovanni Sartori observa que "a televisão chega sempre com rapidez ao lugar onde há agitação, alguém protesta, se manifesta, ocupa edifícios, bloqueia ruas e estradas de ferro e, em suma, ataca algo ou alguém" (Sartori, p.94, 1997; minha tradução). Ele está apontando o papel da mídia na geração da "ingovernabilidade da democracia", estimulando

2 Assim, as fofocas da colunas de notinhas políticas (como o "Painel" da Folha de S. Paulo, por exemplo) representariam o supra-sumo do noticiário político, com seu foco exclusivo nas manobras de bastidores e no "tiroteio" verbal entre adversários. 
um ativismo excessivo, o que transcende a hipótese da espiral do cinismo. Mas seu exemplo ilustra a visão de que os aspectos negativos da ação política são sempre privilegiados no noticiário, o que alimentaria a desconfiança quanto às instituições e às elites.

Thomas Patterson, em seu estudo sobre a cobertura política nos Estados Unidos, também destaca o predomínio da negatividade e o que julga ser a contradição entre o conflito, valor jornalístico, e a busca do consenso, valor político. Em uma frase, boa política não gera boas notícias (Patterson, p.147, 1993). Como resultado, os integrantes da elite política parecem piores do que são - como mentirosos contumazes, por exemplo, enquanto uma análise mais ponderada mostraria que eles se esforçam, em geral, por cumprir suas promessas de campanha.

Mais importante é entender que a forma narrativa própria à notícia favoreceria o enfoque estratégico, que privilegia a busca por poder, em que há atores-adversários claramente definidos, uma disputa muito evidente e momentos de clímax em que a disputa se resolve, ainda que provisoriamente: votações no Legislativo, anúncios de medidas governamentais, decisões judiciais e, sobretudo, eleições. Uma eleição é, sob diversos aspectos, idêntica a um campeonato esportivo, e tende a ser coberta de maneira similar - aquilo que os estudos de jornalismo chamam, há tempos, de abordagem horse-race. Tal como numa corrida, não interessa o que os cavalos estão pensando, apenas saber quem vai chegar na frente.

Assim, por todos estes diferentes motivos, é a mídia que impulsiona uma postura cínica do público, que passa a acreditar que os políticos são necessariamente falsos e incapazes de pensar no bem comum. E os políticos parecem, no relato de Cappella e Jamieson, ocupar a última posição na espiral. O ônus de buscar o benefício público em vez da vantagem pessoal não seria contrabalançado por nenhuma recompensa simbólica, já que a sociedade se recusa a reconhecer qualquer diferencial. Os políticos, assim, se veriam constrangidos a assumir o comportamento cínico, ainda que não 
o desejem, como estratégia de adaptação a uma expectativa social generalizada. É o que se depreende da edificante história do diálogo entre o presidente Bill Clinton, democrata, e o presidente da Câmara, o republicano Newt Gingrich - que, longe das pressões da imprensa, teriam conseguido manter uma conversa "construtiva e cordial", sem a hostilidade que pretensamente marcava sua relação (Cappella e Jamieson, p.3, 1997).

Uma alternativa à espiral do cinismo, mas que também enfatiza a ampliação da desconfiança entre os cidadãos, é a hipótese do declínio do capital social, de Robert Putnam (2000). O conceito de capital social, na versão do autor, refere-se às redes sociais que proporcionam a colaboração entre grupos e indivíduos, tendo por base um patamar mínimo de confiança mútua. Sem discutir os problemas do conceito e da visão normativa da sociedade e da política que subjazem a ele, basta observar que Putnam julga que o capital social está declinante, com graves conseqüências para a saúde do tecido social. A televisão ocuparia um papel crucial no processo, insulando as pessoas em formas de lazer individual e minando a vida comunitária que é o alimento do capital social ${ }^{3}$.

Se a decadência da confiança nos políticos é efeito da mudança de atitudes do público, caberia aos meios de comunicação um papel principal no desencadeamento dessa mudança. É a perspectiva esposada, tanto por autores liberais (no sentido estadunidense) como por Fallows ou os próprios Cappella e Jamieson, quanto por conservadores como Sartori e Putnam. Ilustrada com mais sofisticação pela hipótese da espiral do cinismo, trata-se de uma percepção que aparece com freqüência no discurso de senso comum, em particular o da própria elite política.

3 Para uma crítica à visão de Putnam sobre a TV, ver Gomes (2006). 


\section{O despertar do espírito crítico}

Uma visão oposta é a de que o público se transformou, não no sentido de se tornar cínico, mas no de "abrir os olhos". A elite política sempre teria sido mais ou menos do jeito que as pessoas imaginam que ela é hoje - incompetente, despreocupada com o povo, corrupta. Só que, antes, o público não sabia disso. Um lento processo de aprendizagem teria feito com que os cidadãos comuns deixassem de acreditar na fachada que os políticos criavam.

Embora parte da explicação possa ser creditada a uma pedagogia própria do processo político, o vetor mais importante é claramente a disseminação da informação, proporcionada pela mídia. Se a televisão cobrisse a atuação de George Washington da mesma forma como faz com os presidentes de hoje, a lenda do homem de integridade intransigente nunca se teria firmado - para não falar de Thomas Jefferson, com seus filhos mestiços e bastardos. Joshua Meyrowitz, pesquisador estadunidense que é incluído aqui como representante desta percepção, observa que, se hoje não existem "grandes líderes" similares aos do passado, não é porque faltem candidatos ao cargo, mas porque temos informação em excesso sobre eles (Meyrowitz, p. 270, 1985) ${ }^{4}$.

O esforço interpretativo de Meyrowitz tem um escopo que ultrapassa, e muito, a avaliação dos governantes, ou mesmo, a atividade política como um todo. Ele busca compreender como a mídia eletrônica modificou diversos padrões de comportamento na sociedade, incluindo as relações entre os sexos e entre adultos e crianças, tendo como base a obra de Erving Goffman. De maneira simplificada, para Goffman, o mundo social é uma arena em que os grupos e indivíduos mantêm "representações" de si mes-

\footnotetext{
4 Uma evidência empírica interessante, ainda que lateral, da relação entre informação e desencanto com a política institucional se encontra no fato de que os jovens de 16 e 17 anos do Distrito Federal, que, além de possuírem altos índices de escolaridade e acesso a notícias, encontram-se próximos do poder, são os que menos se alistam como eleitores no Brasil (Florentino, 2006).
} 
mos, adaptadas aos papéis que exercem e às imagens que desejam projetar. Isto estabelece uma divisão entre uma fachada exposta aos olhos públicos e uma retaguarda (backstage), à qual só têm acesso os integrantes do grupo, ou o círculo íntimo do indivíduo. Assim, por exemplo, médicos se apresentam diante de seus pacientes, com um comportamento diferente daqueles que podem adotar junto a seus pares ou seus auxiliares no hospital. O mesmo vale para policiais, professores, garçons, balconistas de loja e assim por diante (Goffman, 1959).

Meyrowitz observa dois efeitos na disseminação dos meios eletrônicos, em especial da televisão. Em primeiro lugar, eles erodem as barreiras dentro do público. Homens e mulheres, adultos e crianças assistem aos mesmos programas, rompendo a segmentação por sexo e idade que era característica da mídia impressa e impedindo, ou ao menos dificultando muito, o controle sobre os conteúdos aos quais os mais jovens têm acesso. Em segundo lugar, a programação da TV tende a revelar a retaguarda de vários grupos sociais, tanto através do jornalismo, quanto do entretenimento. Filmes e seriados mostram que médicos podem ser incompetentes, policiais podem ser corruptos e assim por diante. O maior efeito é exercido sobre as crianças:

Muitos programas de televisão fornecem a crianças de todas as idades visões da retaguarda da vida adulta. Eles revelam como os adultos se preparam e relaxam de seus papéis paternos. Eles mostram às crianças como seus pais se comportam quando não estão com os filhos. Retaguardas similares de professores, policiais, políticos e todas as autoridades adultas são revelados. Em contraste com crianças educadas na palavra impressa, as crianças da televisão aprendem sobre pais deprimidos e policiais desonestos antes de aprenderem os modelos ideais (freqüentemente contraditórios) em casa ou na escola (Meyrowitz, p.154, 1985; ênfases suprimidas; minha tradução). 
Por conta disso, Meyrowitz vai apresentar uma vinculação - instigante, mas talvez um tanto quanto mecânica - entre os avanços da mobilização juvenil e do feminismo, nos anos 1960, e a chegada à idade adulta da primeira geração educada quando a televisão já se encontrava na maior parte dos lares dos Estados Unidos. O que interessa aqui, porém, é observar que a mídia eletrônica ensina que os políticos e os funcionários públicos em geral podem ser maus, isto é, incapazes, mentirosos e/ou corruptos, alertando o público para comportamentos que sempre existiram, mas que, antes, ficavam escondidos na retaguarda.

A cobertura extensiva das atividades dos governantes e dos principais líderes políticos contribui para minar sua credibilidade, exibindo equívocos, hesitações, titubeios que, de outra forma, ficariam longe do conhecimento do grande público. Se antes, era possível testar um discurso em platéias menores, aprimorando-o antes de proferi-lo num evento de maior magnitude, hoje a transmissão ao vivo e mesmo o videotape impedem o procedimento e amplificam qualquer deslize ${ }^{5}$. Por outro lado, problemas localizados na gestão pública se tornam conhecidos por todos, influenciando a avaliação geral do desempenho governamental. Assim, nos Estados Unidos, por exemplo, o público confia mais no representante de seu distrito do que no Congresso como um todo, ou é crítico quanto ao sistema de ensino, mas expressa satisfação quanto à escola local (Nye, p.9, 1997).

Uma explicação paralela vai apontar outra razão para a ampliação da postura crítica do público em relação à elite política, na qual os meios de comunicação de massa também ocupam posição central: a elevação das expectativas. Ao longo do século XX, os cidadãos teriam passado a esperar

5 Como exemplo, é possível especular que, na ausência da mídia, o presidente Lula teria poucos problemas ao afirmar que sexagenários com idéias de esquerda "têm problemas", como fez em dezembro de 2006 - uma boutade simpática para a platéia de empresários que o assistia, mas que causou graves constrangimentos a seus companheiros e aliados históricos, graças à divulgação pelos meios de comunicação. 
mais de seus governos, portanto, a apresentar padrões de avaliação mais exigentes (Samuelson, 1995; Putnam, Pharr e Dalton, p.21, 2000). Parte disso se explicaria pela ampliação na intervenção governamental, com um papel maior na economia e a edificação dos Estados de bem-estar, bem como pela introdução de novos temas na agenda, para os quais se espera a ação dos poderes públicos, como a proteção ao meio-ambiente. Por outro lado, a chamada "globalização" teria reduzido a capacidade de os governos nacionais agirem em favor de seus cidadãos (Putnam, Pharr e Dalton, p.25, 2000). Mas um papel importante cabe à mídia, pelo efeito demonstração que gera. Nosso governo nos parece pior porque não faz aquilo que outros governos fazem e que os meios de comunicação nos mostram.

Fica claro que, se na vertente interpretativa da espiral do cinismo o essencial está nos valores que os meios de comunicação carregam, aqui o foco é a disseminção da informação ${ }^{6}$. Para aqueles que se preocupam especialmente com a manutenção da dominação social estável, o processo de perda de ilusões é negativo. Cidadãos que acreditam nos seus governantes, ainda que eles nem sempre o mereçam, e que estão satisfeitos com o desempenho do governo, mesmo quando podia ser melhor, reduzem os custos de legitimação. Mas para quem busca uma democracia mais substantiva, a maior informação e a ampliação da perspectiva crítica devem ser encaradas como ganhos. O público informado está em condições de meIhorar a interlocução com seus representantes, exigindo maior responsividade (isto é, aprimorando, a accountability).

6 A ênfase no impacto político da informação ampliada transcende os meios jornalísticos. Diferentes redes sociais são capazes de difundir informações que contestam governos e políticos e, por vezes, são eficazes mesmo à margem da mídia. O melhor exemplo é a derrota do governo conservador espanhol nas eleições que se seguiram ao atentado de 11 de março de 2003, na estação ferroviária de Atocha, em Madri. A versão oficial, que responsabilizava os separatistas bascos, foi desmoralizada num movimento em que a mídia ocupou posição secundária e a comunicação horizontal entre cidadãos, por meio, sobretudo, de telefones celulares, foi essencial. 


\section{A decadência das elites}

A percepção de um público informado, que passa a avaliar de maneira mais crítica uma classe política que não é nem melhor nem pior que a do passado, conflita com o senso comum, para o qual há uma decadência dos governantes. Aos grandes nomes da história, contrastam-se os fracos líderes da atualidade. Como comparar Washington, Jefferson e Lincoln a Clinton ou Bush, Churchill a Tony Blair, Juscelino Kubitschek a Lula? A avaliação popular, assim, é continuamente correta. O povo confiava nos políticos confiáveis do passado e desconfia dos atuais, inconfiáveis.

Torna-se necessário, então, entender por que a qualidade da elite política piorou. Para o sociólogo estadunidense Christopher Lasch, o que ocorreu foi um distanciamento entre as elites - em geral, incluindo a política - e o povo, devido à perda do sentido de comunidade e de patriotismo e à concomitante ampliação do cosmopolitismo. Esvai-se o sentido de pertencimento a um local, que vinculava a elite à massa e fazia com que a primeira se sentisse obrigada a servir, de alguma maneira, à segunda; em seu lugar, impõe-se o "multiculturalismo", "um bazar global em que as culinárias exóticas, as roupas exóticas, a música exótica e os costumes tribais exóticos podem ser saboreados indiscriminadamente, sem que se façam perguntas ou se exijam compromissos" (Lasch, p.14, 1995).

A palavra crucial na citação é compromissos. As elites atuais se descomprometem das comunidades a que antes estavam vinculadas. A posição de Lasch, a despeito de sua origem na esquerda estadunidense, é extremadamente conservadora - ele chega a apontar a emancipação feminina e a dessegregação racial dos bairros como parte do problema. Mas encontra ecos na obra de um autor "progressista" como o sociólogo polonês Zygmunt Bauman, que anota como "elites extraterritoriais cada vez mais globais" se distanciam do "restante da população, cada vez mais 'localizada'" (Bauman, p.9, 1998). O foco de Bauman, porém, não é a decadência das elites e sim, a ampliação da desigualdade social. 
Na narrativa de Lasch, a mídia não ocupa um papel determinante, ainda que sejam dedicadas algumas páginas à denúncia da televisão como maior propagadora do "cinismo que sempre esteve no mercado" (Lasch, p.116, 1995). Antes, as causas deveriam ser procuradas no avanço do individualismo e do hedonismo e no declínio do patriotismo, da religiosidade e dos valores familiares.

Em outras análises, focadas de maneira mais específica na perda de qualidade da elite política, os meios de comunicação recuperam centralidade. Três movimentos paralelos podem ser apontados. O mais importante deles indica que o novo ambiente da competição política, em grande medida configurado pela mídia, conduz a escolhas populares piores. A exposição mais extremada desta idéia está na obra de Giovanni Sartori, o cientista político italiano que é, também, o mais eloqüente defensor do caráter eminentemente seletivo do processo eleitoral ${ }^{7}$.

Em seu panfleto contra a influência social da televisão, Homo videns, ele a condena por imbecilizar o público, tornando-o incapaz de pensar. Trata-se de algo inerente ao meio, uma vez que "a imagem é inimiga da abstração" (Sartori, p.84, 1987; minha tradução) e o raciocínio abstrato é essencial para a compreensão do mundo. Com seu mundo intelectual alimentado pela TV, o eleitorado obviamente é incompetente para acompanhar as questões políticas e escolher entre os candidatos. E os governantes se vêem levados a adotar medidas de curto prazo, ainda que menos eficazes, já que o eleitorado - que precisam satisfazer para permanecer no poder - não consegue entender providências mais complexas.

Da leitura de Sartori se depreende com clareza que a crítica à televisão está embutida numa percepção que desconfia, em primeiro lugar, da democracia. O risco é a ampliação da democracia para além da representa-

7 "As eleições foram concebidas, então, como um instrumento de seleção no sentido qualitativo do termo" (Sartori, 1987, vol. 1, p. 193). 
ção estrita, já que o povo - (mal) informado pela televisão - controlaria permanentemente a ação de seus representantes (Sartori, p.124, 1987). O mérito não encontraria espaço; a crítica de Sartori de que, para os índices de audiência, "contar com Churchill entre o público tem o mesmo peso que contar com seu porteiro" (Sartori, p.142, 1987; minha tradução), vale também para a eleição no regime democrático. Assim, se percebe que, sob esta perspectiva francamente elitista, o problema não é tanto que a televisão idiotize o público, mas que ela lhe dê a ilusão de compreender os negócios públicos ${ }^{8}$.

O segundo movimento explicativo da decadência das elites políticas se vincula à perda de centralidade dos partidos. A mídia eletrônica contribui para personalizar as disputas de poder, tornando os partidos menos centrais, seja para os candidatos (que prescindem deles para se comunicar com o público), seja para os eleitores (que pouco os levam em conta na hora de fazer suas escolhas), como observam Sartori e muitos outros (por exemplo, Wattenberg, 1998). Condenados durante séculos pela tradição do pensamento político, que via neles a organização de interesses parciais e, portanto, uma ameaça à obtenção da vontade geral, os partidos vão ser exaltados a partir das primeiras décadas do século XX, como as ferramentas essenciais da política democrática: "a democracia moderna é impensável sem os partidos" (Schattschneider, p.1, 1942; minha tradução). Sem partidos fortes, os candidatos perdem o lastro programático e são tentados a se lançar em num jogo em que a construção da imagem pública individual é o único elemento que importa. Disputas políticas personalizadas são o território dos spins doctors, dos marqueteiros, dos discursos vazios que eludem as questões de fundo.

Por fim, os meios de comunicação de massa pioram a qualidade das decisões políticas por exigirem respostas apressadas. Quando mais rapidamente a informação circula, mais rápida deve ser a reação do líder político, sob pena de parecer "vacilante" - quem não se lembra do pasmo de George 
W. Bush, ao ser informado dos atentados do 11 de setembro de 2001, em imagens que foram exploradas à exaustão por Michael Moore? As decisões devem ser tomadas quase de "bate-pronto", a tempo de responder aos repórteres do rádio ou da TV. Com isso, ou as decisões pouco pensadas são modificadas depois, o que reforça a imagem de vacilante, ou, para evitar o estigma, são mantidas. Isto vale para o governo, mas também para a oposição, cujos líderes, muitas vezes, comprometem-se de público com idéias sobre as quais não refletiram.

Na constituição da ilha de Utopia, Thomas More indicou que, quando é feita uma proposta legislativa, ninguém pode discuti-la no mesmo dia, para impedir que, por orgulho, fiquem presos às bobagens ditas sem reflexão (More, p.226, 1516). Os meios de comunicação modernos praticamente exigem dos líderes políticos o comportamento oposto.

Em suma, os meios de comunicação - em particular, a televisão reduziriam a capacidade cognitiva do eleitorado, ao mesmo tempo em que o fariam imaginar que possuiria mais informação sobre a vida política, levando a piores escolhas; enfraqueceriam os partidos políticos, tornando a política uma disputa entre personalidades, e obrigariam os líderes políticos a apresentar respostas apressadas aos acontecimentos. Desta forma, contribuiriam para a redução na qualidade da tomada de decisões.

\section{Conclusões}

É difícil negar que a abordagem da mídia sobre a política mudou nas últimas quatro ou cinco décadas. Embora o papel de watchdog seja, desde o princípio, constitutivo da ideologia do moderno jornalismo, a cobertura se tornou mais agressiva a partir do momento em que se erode a crença de que, como regra, o governo é o fiel intérprete dos interesses da nação - o 
que, nos Estados Unidos, teria acontecido a partir da derrocada no Vietnã e do escândalo de Watergate ${ }^{9}$.

Porém, a existência de uma associação entre mudança no discurso da mídia e mudança nas disposições do público não permite estabelecer, por si só, uma direção causal, como bem anota Norris (p.206, 2000). E, na verdade, as transformações na cobertura jornalística - e também nas representações da programação de entretenimento - sobre a política precisam, elas mesmas, receber explicações. As hipóteses do determinismo tecnológico (a causa é o surgimento da televisão) e do "espelho do real" (a mídia apenas reflete as mudanças na política) são, ambas, simplistas e insuficientes.

As três explicações discutidas ao longo deste artigo têm diferentes graus de complexidade. O quadro 1, abaixo, sumariza três características delas - sobre quem e de que forma se dá a influência dos meios de comunicação e qual a posição dos jornalistas -, embora deva ser levado em conta que existem diferenças no seio de cada vertente.

Quadro 1. A mídia nas narrativas sobre o declínio da confiança na classe política

\begin{tabular}{|c|c|c|c|}
\hline & $\begin{array}{c}\text { a influência da } \\
\text { mídia se dá } \\
\text { primordialmente... }\end{array}$ & $\begin{array}{c}\text { essa influência } \\
\text { toma a forma de... }\end{array}$ & $\begin{array}{l}\text { os jornalistas } \\
\text { são.. }\end{array}$ \\
\hline espiral do cinismo & $\begin{array}{l}\text { tanto sobre o público, } \\
\text { quanto sobre os políticos }\end{array}$ & $\begin{array}{c}\text { disseminação } \\
\text { de valores }\end{array}$ & $\begin{array}{l}\text { profissionais } \\
\text { "bitolados" }\end{array}$ \\
\hline $\begin{array}{l}\text { despertar do } \\
\text { espírito crítico }\end{array}$ & sobre o público & $\begin{array}{l}\text { difusão de } \\
\text { informação }\end{array}$ & $\begin{array}{l}\text { provedores de } \\
\text { informação }\end{array}$ \\
\hline $\begin{array}{l}\text { decadência } \\
\text { das elites }\end{array}$ & sobre os políticos & $\begin{array}{c}\text { indução a } \\
\text { transformação } \\
\text { de comportamento }\end{array}$ & $\begin{array}{l}\text { conturbadores } \\
\text { do jogo político }\end{array}$ \\
\hline
\end{tabular}

9 A referência aos Estados Unidos é importante, na medida em que seu jornalismo influencia o de grande parte do mundo, incluindo o Brasil. 
Para a hipótese da espiral do cinismo, os valores que a mídia dissemina atuam igualmente sobre o público e sobre os políticos. Os jornalistas incorporam uma perspectiva cínica devido à sua especialização excessiva, que os leva a não ver, na política, nada além dos jogos de poder. Na hipótese do despertar do espírito crítico, a informação provida pela mídia erode as ilusões do público. E, na hipótese da decadência das elites, por fim, os jornalistas impõem seu ritmo e seus imperativos profissionais a políticos sedentos por visibilidade, modificando (para pior) seu comportamento.

Ainda que cada uma das três explicações contribua para iluminar fenômenos reais, elas tendem a apresentar percepções muito unilaterais. E a ênfase no papel dos meios de comunicação de massa ignora a presença de outros fenômenos, pelo menos igualmente importantes para a compreensão do processo.

De maneira bastante esquemática, na forma de hipóteses ainda embrionárias, é possível indicar duas transformações mais amplas, uma cultural e outra política, que afetaram o público e também a mídia. Conforme disse Paul Ricœur (1965), o final do século XIX e o início do século XX nos legaram, através das obras de Marx, Nietzsche e Freud, uma "hermenêutica da suspeição", segundo a qual qualquer discurso busca esconder interesses políticos aos quais serve. Hoje, tal percepção ingressou também na cultura popular, cabendo à indústria cultural um papel importante, mas não exclusivo, na sua disseminação.

Noções como "ideologia", "racionalização" e correlatas ensinam que correntes de subtextos deslizam por baixo das intenções ostensivas, que os valores se amoldam aos interesses, que a linguagem esconde pelo menos tanto quanto desvela - e, sobretudo, que isso não é o desvio, a patologia ou a exceção, e sim, a regra, discernível mesmo nos discursos proferidos de "boa fé". A desconfiança em relação aos políticos é elemento de uma desconfiança generalizada, em relação a qualquer discurso de poder, o que, aliás, inclui o próprio discurso da mídia ${ }^{10}$. 
Por outro lado - e esta é a segunda transformação, talvez ainda mais relevante do que a anterior -, a primeira metade do século XX foi o grande momento de expansão da democracia. Paulatinamente novos grupos foram incorporados à cidadania política, o que é emblematizado pela extensão da franquia eleitoral aos trabalhadores, às mulheres, aos membros das minorias étnicas e aos mais jovens. Os movimentos contestatórios incluíam, assim, um componente de inserção no sistema político representativo. Quando essa inserção está praticamente concluída, os limites da representação se tornam mais evidentes. $\mathrm{O}$ descrédito se generaliza no momento em que não é mais possível atribuir as falhas de responsividade do sistema à ausência de direitos formais de participação.

Sob esta perspectiva, a desconfiança em relação à classe política remete ao fato de que ela é estruturalmente incapaz de cumprir os compromissos com seus constituintes, dados os vieses da representação política formal. Não se trata, assim, de uma elite política que piorou, ou de uma população que abriu os olhos quanto aos defeitos de seus governantes, mas de um processo histórico que evidenciou os limites da democracia eleitoral que temos.

Nenhuma das duas hipóteses pretende fornecer uma resposta exaustiva à questão. Elas sinalizam, porém, na direção de explicações mais amplas, que entendam os meios de comunicação de massa, dentro do ambiente cultural e político e, não, como variáveis independentes.

confiáveis - não afeta sua posição estrutural de provedor de informações socialmente relevantes. Sob certo ponto de vista, pouco importa se acredito ou não naquilo que a imprensa me diz: eu preciso de informações para me situar no mundo e aquelas são as únicas de que disponho (ver Miguel, 1999). O mesmo, mutatis mutandis, se pode dizer do discurso político. Ainda que os partidos, por exemplo, desfrutem de legitimidade decrescente, exercem o monopólio da representação política formal, não restando ao cidadão comum senão as alternativas de escolher um deles para votar, confiando ou não, ou se omitir. 


\section{Referências}

ALMOND, Gabriel A. e VERBA, Sidney. The civic culture: political attitudes and democracy in five nations. Princeton: Princeton University Press, 1963.

BAUMAN, Zygmunt. Globalização: as conseqüências humanas. Rio de Janeiro: Jorge Zahar, 1999.

CAPPELLA, Joseph N. e JAMIESON, Kathleen Hall. Spiral of cynicism: the press and the public good. Oxford: Oxford University Press, 1997.

DAHL, Robert A. A democratic paradox? Political Science Quarterly, vol. CXV, no 1. Washington, pp. 35-40, 2000.

FALLOWS, James. Detonando a notícia: como a mídia corrói a democracia americana. Rio de Janeiro: Civilização Brasileira, 1997.

FLORENTINO, Renata. Rebeldes invisíveis: imaginário de jovens brasilienses relacionado à política. Monografia de graduação em Sociologia. Brasília: Universidade de Brasília, 2006.

GOFFMAN, Erving. The presentation of self in everyday life. New York: Anchor Books, 1959.

GOMES, Wilson. Capital social, democracia e televisão em Robert Putnam ou Tocqueville não via TV. Paper apresentado ao 15을 Encontro Anual da COMPÓS. Bauru, 6 a 9 de junho, 2006.

HUNTINGTON, Samuel P. The United States, em CROZIER, Michel J., Samuel P., 1975.

HUNTINGTON e WATANUKI, Joji, The crisis of democracy: report on the governability of democracies to the Trilateral Comission. New York: New York University Press.

LASCH, Christoher. A rebelião das elites e a traição da democracia. Rio de Janeiro: Ediouro, 1995.

MEYROWITZ, Joshua. No sense of place: the impact of electronic media on social behavior. Oxford: Oxford University Press, 1985.

MIGUEL, Luis Felipe. O jornalismo como sistema perito. Tempo Social, vol. 11, no 1. São Paulo, pp. 197-208, 1999. 
MIGUEL, Luis Felipe. Política e mídia no Brasil: episódios da história recente. Brasília: Plano, 2002.

MIGUEL, Luis Felipe. Impasses da accountability: dilemas e alternativas da representação política. Revista de Sociologia e Política, no 25. Curitiba, p.165-78, 2005.

MORE, Thomas. A Utopia. São Paulo: Nova Cultural, (1988), 1516.

NOELLE-NEUMAN, Elisabeth. La espiral del silencio. Opinión pública: nuestra piel social. Barcelona: Paidós, (1995), 1993.

NORRIS, Pippa. Introduction: the growth of critical citizens?, em NORRIS, Pippa (ed.), Critical citizens: global support for democratic governance. Oxford: Oxford University Press, 1999.

NORRIS, Pippa. Critical citizens: global support for democratic governance. Oxford: Oxford University Press, 1999.

NORRIS, Pippa. A virtuous circle: political communication in postindustrial societies. Cambridge: Cambridge University Press, 2000.

NYE, Jr., e S., Joseph. Introduction: the decline of confidence in government, em NYE, Jr., Joseph S., Philip D. ZELIKOW e David C. KING (eds.), Why people don't trust government. Cambridge (MA): Harvard University Press, 1997.

NYE, Jr., S., Joseph e D. ZELIKOW , Philip. Conclusion: reflections, conjectures, and puzzles, em NYE, Jr., Joseph S., Philip D. ZELIKOW e David C. KING (eds.), Why people don't trust government. Cambridge (MA): Harvard University Press, 1997.

NYE, Jr., S., Joseph, D. ZELIKOW, Philip e C. KING, David. Why people don't trust government. Cambridge (MA): Harvard University Press, 1997.

PATTERSON, Thomas E. Out of order. New York: Vintage Books, 1993.

PHARR, Susan J. e D. PUTNAM, Robert. Disaffected democracies: what's troubling the Trilateral countries. Princeton: Princeton University Press, 2000.

PUTNAM, Robert D. Bowling alone: the collapse and revival of American community. New York: Simon \& Schuster, 2000. 
PUTNAM, Robert D., J. PHARR, Susan e J. DALTON, Russell. Introduction: what's troubling the Trilateral democracies?, em PHARR, Susan J. e Robert D. PUTNAM (eds.), Disaffected democracies: what's troubling the Trilateral countries. Princeton: Princeton University Press, 2000.

RICOEUR, Paul. De l'intérpretation: essai sur Freud. Paris: Seuil, 1965.

SAMUELSON, Robert. The good life and its discontents: the American dream in the age of Enlightment, 1945-1995. New York: Times Books, 1995.

SARTORI, Giovanni. A teoria da democracia revisitada, 2 v. São Paulo: Ática, (1994), 1987.

SARTORI, Giovanni. Homo videns: la sociedad telediriga. Buenos Aires: Taurus, 1997.

SCHATTSCHNEIDER, E. E. Party government. New York: Farrar and Rinehart, 1942.

WATTENBERG, Martin P. (1998), The decline of American political parties, 19521996. Cambridge (MA): Harvard University Press, 1998. 
Sociologias, Porto Alegre, ano 10, no 19, jan./jun. 2008, p. 250-273

\section{Resumo}

Já há algumas décadas, verifica-se uma crise generalizada de confiança nas elites políticas, tanto em velhas, quanto em novas democracias. O artigo explora três vertentes explicativas para o fenômeno: ele se deve ao cinismo dos cidadãos atuais (as elites são tão boas quanto antes, mas o público não acredita), à ampliação de sua percepção crítica (as elites eram tão ruins quanto hoje, mas o público não percebia), ou a uma queda efetiva na qualidade da classe política. Em todas as três explicações, os meios de comunicação de massa desempenham um papel crucial.

Palavras-Chave: Legitimidade política. Elites políticas. Mídia e política.

Recebido: 07/03/07

Aceite final: 24/09/07 


\section{INTERFACES}

INTERFACES

\section{The media and the declining trust in politics}

\section{Luis Felipe Miguel}

For a few decades, there has been a general crisis of confidence in the political elites, both in old and new democracies. This article discusses three possible explanations for the phenomenon: it is due to the cynicism of the citizens of today (the elites are as good as they were before, but the public does not believe it); the increase of the critical perception (the elites were as bad as they are now, but the public did not perceive it); or an actual decline in the quality of the political class. In all three explanations, the mass media plays a key role.

Keywords: political legitimacy, political elites, media and politics. 